\title{
DIGITAL REBIRTH OF THE GREATEST CHURCH OF CLUNY MAIOR ECCLESIA: FROM OPTRONIC SURVEYS TO REAL TIME USE OF THE DIGITAL MODEL
}

\author{
J. Landrieu, C. Père, J. Rollier, S. Castandet, G. Schotte
}

Arts et Metiers ParisTech, CNRS, LE2I, Institut Image - Rue Porte de Paris 71250 CLUNY, FRANCE (landrieu, pere, rollier, castandet, schotte)@ensam.eu

Commission V, WG 4

KEY WORDS: Reverse Engineering, laser scanning, pre-computed rendering, real time rendering, digital workflow, product structure, Augmented Reality

\begin{abstract}
:
Our multidisciplinary team has virtually reconstructed the greatest church of the Romanesque period in Europe. The third church of the Abbey of Cluny (12 th c.) has been destroyed after the French Revolution, leaving only $8 \%$ of the building standing. Many documents have been studied, to include the latest archaeological knowledge in the virtual model. Most remains have been scanned for CAD restitution. The mock-up of the church needed 1600 different numerical files, including the scanned pieces and the anastylosis of a Romanesque portal, a Gothic façade and a mosaic pavement. We faced various difficulties to assemble the different elements of the huge building, and to include the digitized parts. Our workflow consisted in generating geometrical shapes of the church, enriched with metadata such as texture, material... The whole mock up was finally exported to dedicated software to run the rendering step. Our work consisted in creating a whole database of 3D models as well as 2D sources (plans, engravings, pictures...) accessible by the scientific community. The scientific perspectives focus on a representation in virtual immersion of the grand church at scale 1 and an access to the digital mock-up through Augmented Reality.
\end{abstract}

\section{INTRODUCTION}

The Romanesque church of Cluny was the greatest of all Europe and designated as the "Second Rome". Located at the frontier of the German Empire and the French Kingdom, the abbey of Cluny played a very prominent role in the history of Medieval Ages, from its foundation in 910 to the end of the 12th century.

The destruction of the church began in the $18^{\text {th }}$ century after the French Revolution and continued during the $19^{\text {th }}$ century, leaving only few parts of the choir and some walls of the antechurch (8\% of the abbatial church remains standing).

For the $1100^{\text {th }}$ anniversary of its foundation (910-2010), an important work of archaeological reconstitution has been financed and conducted.

Three different aspects justified this task, on one hand the touristic affluence and the difficulty to understand the archaeological remains called for a virtual restitution. Secondly many specialists studied this site, on multiple aspects, a rich documentation was available but scattered in different sites and never compiled. Thirdly, the rapid degradation of the ruins also needed an urgent memorizing, in order to constitute a numeric conservatory.

The scope of imagery was to develop new methods of studying ancient buildings, an ambitious process of creating a virtual environment from multiple data sources.

On the technical aspect the challenge for the engineers was to create a digital model according to the latest scientific researches, including the archaeological excavations and the remains including the study of the documentary sources. This implied the use of special algorithms to offer the best restitution of the architecture. The engineering school of Arts et Métiers has developed for this task the Gunzo project, a multi disciplinary research team.

\section{PROJECT BACKGROUND}

The Gunzo project, a project of applied research, is today one of the main French and international references in the use of new technologies in the heritage field. This multidisciplinary platform of advanced technologies is dedicated to the dissemination of heritage and technology. A team of 15 engineers, archaeologists, historians, geographers has worked on the digital mock-up of Cluny III, the third and greatest abbatial church.

Working within the Institut Image (a scientific laboratory of the Arts et Métiers) and in close partnership with the Centre des monuments nationaux and on-situ company, the project benefitted from European funds as well as some from the local and regional authorities. Cluny's digital background started almost 20 years ago, with a first mock-up of the church that lead to a movie in computer generated images. In 2004, a new digital version was born, as well as a stereoscopic movie.

\section{2010 TARGETS AND BEYOND}

The project has a double objective. The first is scientific and multi-field. The intellectual process of the digital restitution allowed the archaeologists and historians to better apprehend the databases and the knowledge accumulated on the grand church, but also to confront the sources, their uncertainty and discordance exposed to the new data resulting from the more recent archaeological excavations.

The third church of Cluny remains an extraordinary building; the monument is poorly represented, graphically, before its destruction. The genius of the builders was to be able to transpose in the stone the image of Paradise. The carved and painted decoration was of a quality, showing the prestige of the abbots. 
For the virtual restitution, medieval architecture and its codes make it possible to propose a coherent 3D modelling of the volumes. It is not the same for the decoration, since only a negligible part of the fragments reached us. The stones reserves of Cluny museum count more than 20000 fragments, of varied quality: capitals, frieze, fragments of sculptures, scattered elements. Although the number of fragments seem consequent, it is very difficult to represent the richness of the sculpture and painting. It was necessary to elaborate various hypothesis and to discuss them with different specialists, in order to propose plausible assumptions.

The second objective of the project is the mediation towards the public. The site is visited, each year, by more than 100000 people (more than 150000 in 2010). To answer the frustration of the visitor who has difficulties in perceiving the influence of the church in the current urban city, the project Maior Ecclesia proposes various virtual representations of the church in the visit tour of the abbey. A $15 \mathrm{~min}$ long stereoscopic film is projected in a 50 seats room on an $8 \mathrm{~m}$ wide screen. Four fixed devices of Augmented Reality are distributed on the visit circuit, allowing to the visitors to combine, by one look, real vision of the vestiges and virtual vision of the building.

The prospects relate now to an exploitation of the digital model in virtual immersion. This representation on scale 1 , in virtual reality rooms, makes it possible to navigate in the Maior Ecclesia graphical restitution and to interact with the digital model and its metadata in real time. Our step turns to the exploitation of the video game engines, like a serious gaming applied to the heritage and tourism.

The other strategic axis of innovation of the laboratory aims at proposing other uses of mobile devices such as PC tablets or see-through glasses. By proposing a geo-localized and geooriented virtual representation, on site, by the means of clouds computations, the step aims at presenting an evolution of a place through different time periods, by measuring the evolution of a city, from the point of view of a responsible urban development.

This temporal representation of the city and the landscape also brings us to an active step towards Geographical Information Systems (GIS) and the integration of detailed 3D models in an urban context.

\section{DIGITAL RESTITUTION OF CLUNY III}

We previously presented our work (Pere et al, 2009), and this article will present our progression. This section will also explain the whole numerical workflow from the digitalization of the remains to the pre-computed rendering that lead to the movie.

The whole process is described below (Figure 1). It is interesting to notice that we settled our own pipeline for literature (Remondino et al, 2009; Stamos et al, 2009) usually focuses on modelling still existing buildings. Our case of study also managed destroyed elements. Nevertheless we selected many interesting points especially in (Happa et al, 2010)'s state of the art in order to elaborate our workflow.

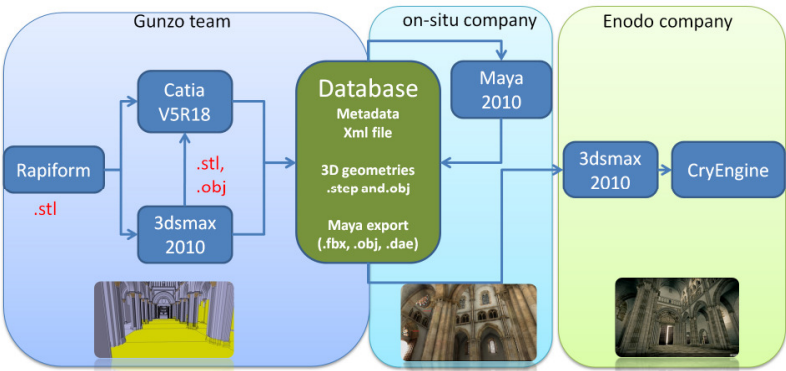

Figure 1. From digital scanning to full scale visualization

\subsection{Starting from the remains}

The abbatial church is constituted of different architectural parts, from the piers, the great arcades, the blind arcading, the windows and all decorative elements such as capitals, frieze and portals. We will see later that we identify them as components. All of these parts of the church do not require the same accuracy. That is why we chose different devices to capture the existing parts.

The main shapes of the building were acquired with a Trimble GS 200 (Trimble). This device's accuracy is about $10^{-2} \mathrm{~m}$, targeting from the ground to the top of the bell tower (peaking at 50 meters), and enabled us to save every subset of the remains. Thanks to different sight locations, the whole construction could be re-assembled in dedicated software.

A representative selection of the decorative remains -the lapidary elements- was also scanned. Many of them fell down when the church was being destroyed but a few of them still stand in their right place, e.g. the capitals in the primary transept; peaking at 30 meters high. We used for all lapidary elements a FARO poly-articulated (5 axis) arm, on which a MMD100 and MMD50 probe was mounted (Metris ModelMaker). This enabled us to reach a higher accuracy, in other words: $10^{-5} \mathrm{~m}$. Most of the lapidary elements were stored in the Archaeological and Art museum of Cluny. A large digitization survey aimed at gathering digital data of these remains, in order to integrate them into the next version of the mock-up. This is actually the huge innovation in comparison with the previous version, in which such an integration of digitized elements had never been undertaken before.

Thirty-six capitals (in the south arm of primary transept) were digitized, as well as sixty fragments of the museum, fifteen sculpted supports of missing statues (in the Jean de Bourbon Chapel), and more than ten remains of the choir's capitals...

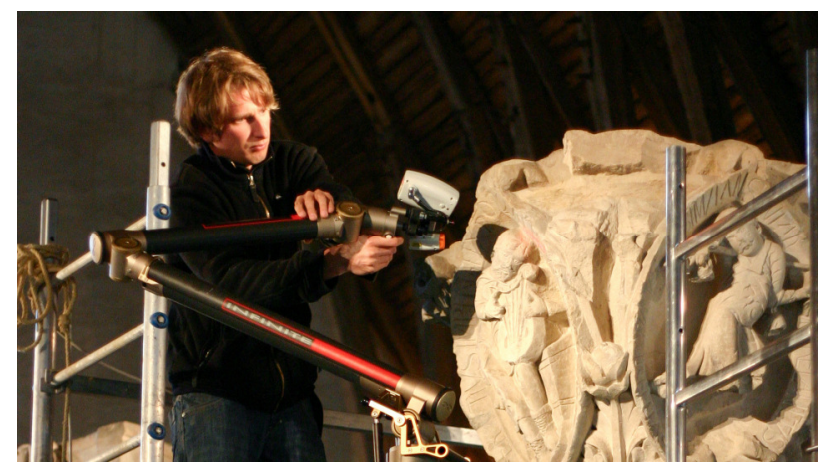

Figure 2. 3D scanning of choir's capitals 


\subsection{Featuring a structured database}

This first step generated STL format data with ASCII representation. Natively they are soup of disorganized poly faces. The objective was to establish a semantic-based set of data, learnt from (De Luca et al, 2007)'s works. They would be computed either for the reverse-engineering step or for posttreatment. Before, we set up a generic structure of the future database. Indeed the need of a strict organization rapidly arose. Thus we decided to adopt a concept coming from the automotive and aeronautics industry: the Product structure (Hvam, 1999). This method led us to break up our abbatial church into sections, which were also divided into sub-sections. These constituted an assembly of elements which are at the end, sets of sub-elements. We aimed at establishing a good working method, suitable for the study of any other building. This spatial cut ruled by architectural concerns logically led to denomination issues: How could we name the third version of the abbatial church of Cluny, also called Cluny III. We based our work on the Merimée classification (Mérimée). Then the breakup of the monument followed the principles used in architecture, as well as a scientific logic. The sections correspond to main parts of the church: nave, choir, antechurch, and its Romanesque and Gothic facades, primary transept. For example, the antechurch is divided into a large central aisle, and smaller north and south ones. These are also organized in five bays with a group of imponent piers, overhung by capitals, blind arcading windows. Below, the sub-elements are for instance the floor, the walls, the roof, vaults and if necessary columns, piers, capitals, frieze.

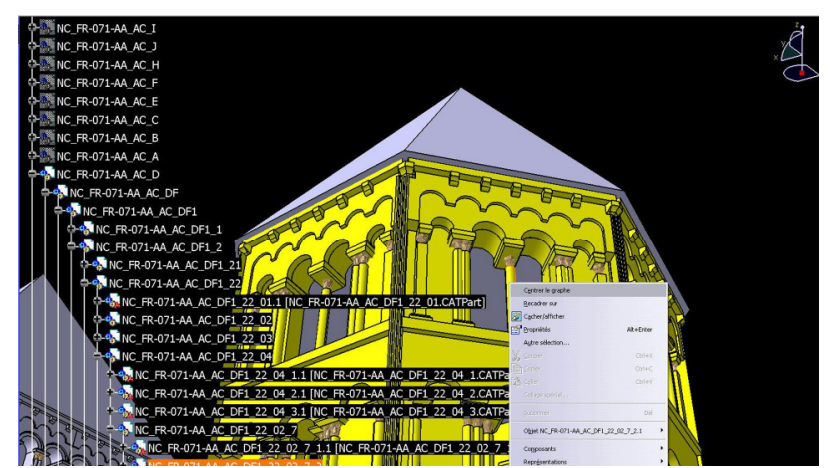

Figure 3. Mock-up product structure and naming

We aimed at storing all amount of data in a web database, with free access to the scientific community. This shared database is currently under construction but it will soon be available for access and contribution. On that topic we actually fed our methods with existing researches results (Guarnieri et al, 2009).

\subsection{Modelling the abbatial church}

The software used to model the church is CATIA V5 R18, edited by Dassault Systèmes. This CAD software is usually utilized in automotive and aeronautics to set up digital mock ups. We opted for CATIA because of the notion of Product Structure that it embeds: Most geometric elements are both assemblies and components. As a consequence a hierarchical structure arose from this data organization. However we faced to problems linked to the digital workflow. Indeed, CATIA performed geometric models which were secondly imported in Maya software. But it was not possible to reverse the process. CATIA was only used to model the components of the church. These were constituted of geometry but also metadata, such as parameters. They characterized their localization (indoor- outdoor), existence (missing component or not), type (floor, wall, vault...), registration status and finally the component's material. These specifications were useful in case of specific requests on the model.

Entry data were either 3D-points clouds or 2D-draft, engraving and plans, or text documents. Documentary sources were numerous and led us to frequently confront contradictory theses. The final decision was of the responsibility of our scientific committee.

On one hand, 3D objects were simply modeled -with the help of measures of shapes on the plans, or drafts. It concerned missing parts of the building. On the other hand entry data was a points cloud: Either the digital object was part of the lapidary elements- then it was processed with specific software in order to be implemented later in the model. Or it was part of the main shapes of the building: 3D objects were thus generated by reverse engineering methods, also imported from the manufacturing industry. That means we used the point cloud as a support to model the basic generator of the CAD components. (De Luca et al, 2006; Chevrier, C. et al, 2009) proposed method for modeling complex architectural elements (such as gothic style). We focused on the interest of settling a knowledge-based and organized model. For instance, the elements named "vault" were ruled by parameters, such as height, value of formeret arch and cross-springer. This method is close to Generative Modeling Language (GML, 2008) but is adapted to CATIA components.

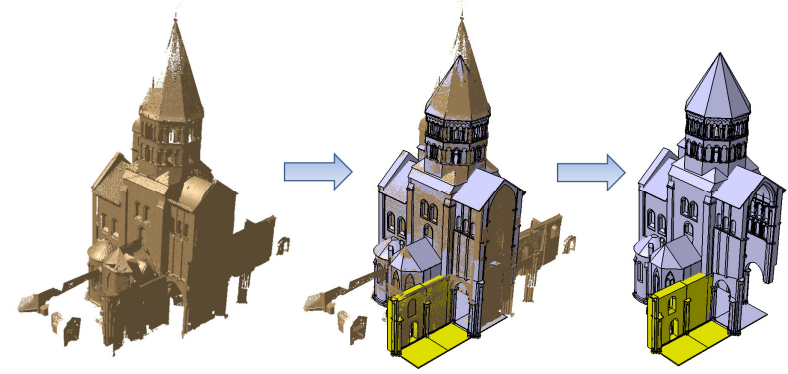

Figure 4. Reverse engineering method

A routine finally created a XML file, organized following the Product Structure. It translated the CAD model into a polyedric mesh imported on the rendering software (Maya). An iterative process (in case of model changes) is hard to implement without redundant operations, for it is not possible to convert a polyedric set into a CAD model.

As far as the building evolved during times, we focused on the fifteenth century release. Most of current remains were reliable. But it occurred that renovation works had been locally led. Even if we could suppose that historical authenticity was preserved, certain elements lacked of reliability.

We aimed at modeling a digital reconstruction of the abbatial church Cluny III, as faithful as possible. Our progression was frequently supervised by a collegial panel of archaeologists, architects and art historians. A few very particular points needed the advices of external experts, particularly when documentary sources happened to be contradictory.

The archaeological authenticity of the mock-up required a lot of verifications, concerning the forms and dimensions of the windows, doors and vaults. The choir was a particularly complex part, in which we included parts of decoration, according to the archaeological remains. 
The pavement, known from preserved small mosaic fragments, was reconstructed with $2 \mathrm{D}$ techniques and textured in order to give it the ancient marble aspect. The comparison with other pavements of the same kind, particularly in Rome, and the study of the geometrical system of the Cluniac pavement have lead us to the hypothesis of a ten meter long floor, leading to the main altar of the monastic choir. The intersection of four circles was a particularly interesting motif to place in front of the altar and in correspondence with the big transept. On this matter, although the model should refer to the fifteenth century, we chose the current floor; because of Augmented Reality issues.

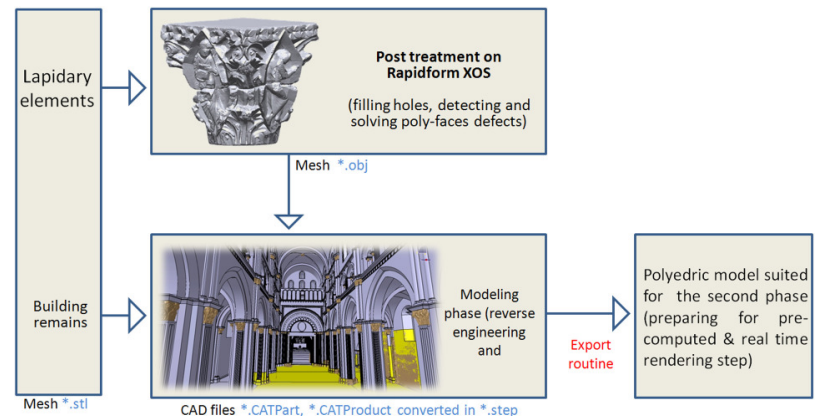

Figure 5. General Workflow for Phase 1

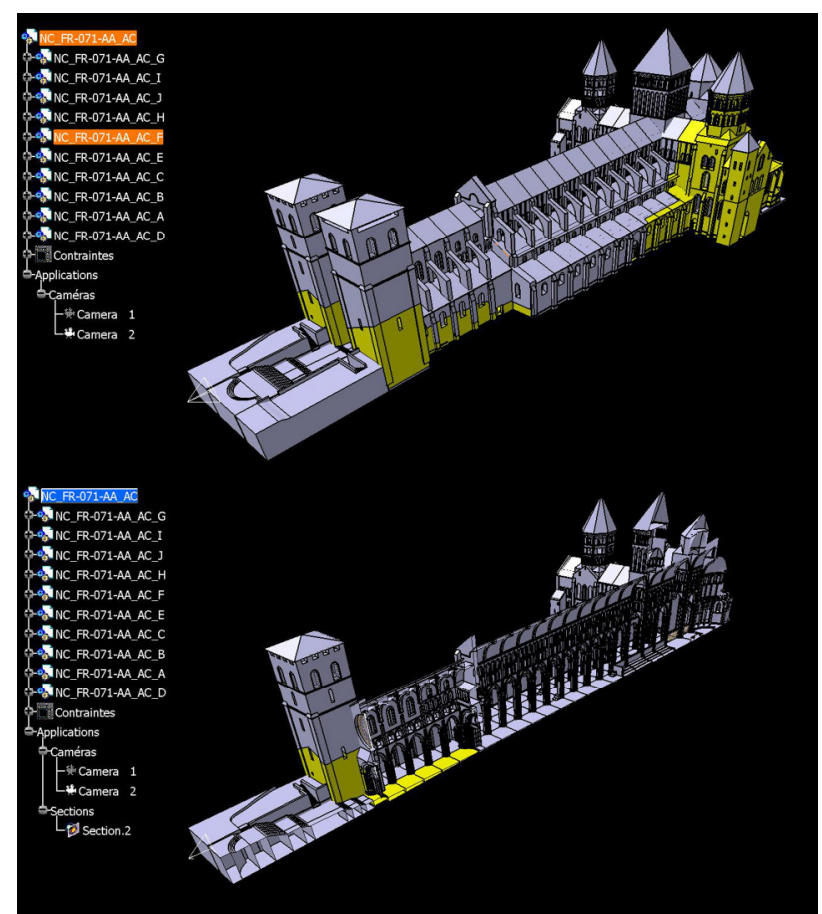

Figure 6. Exterior and interior of the full digital mock-up

\subsection{The second phase: the model's pre-computed rendering}

We have a 3D geometric representation of Maior Ecclesia at this late stage of digital restitution. We tried to reconstitute virtually material, paint and sculpture by means of a computer graphic process. To this end, our database (polyedric mesh and XML file) was entrusted to on-situ company. This company is specialized in cultural mediation by new technologies of image.

First of all, a MEL script was developed in Maya software in order to get all data back (product structure, mesh and metadata). Every modification made in CATIA was transferred in Maya, and thus updated the database. This point was crucial. Indeed, scientists may make new discoveries in the future, which should be reachable by the scientific community. In that objective, (Guarnieri et al, 2009) proposes an interesting method to store a 3D-objects database with open-source tools. The import of metadata enabled to sort polyedric meshes into specific layers. It was thus possible to display $3 \mathrm{D}$ components by queries (existing parts, missing sections, lapidary elements...).

Then, a common 3D computer graphics process was used (lighting, procedural texture generation and mapping, camera animation). The different $2 \mathrm{D}$ image of the prepared scene was generated by the render engine Mental ray. These 2D images are the result of a process of digitally assembling multiple images (diffuse, specular, ambient occlusion...). We made the choice to render separately these elements in order to have the best control on graphic chain. Furthermore, it was necessary to operate this graphic pipeline for using incrustation, match moving in compositing software (shake).

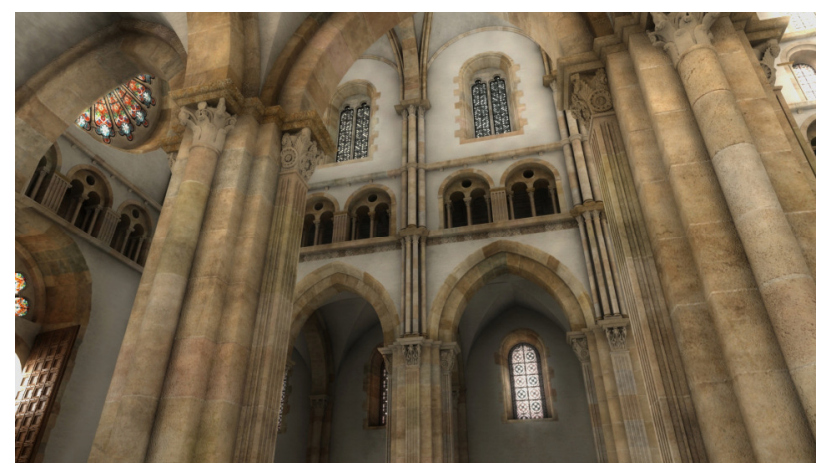

Figure 7: Rendering picture of the first nave with Maya (c) Arts et Métiers ParisTech, Centre des monuments nationaux, on situ

\section{PAST AND CURRENT RESEARCHES}

The archaeological excavations by K. J. Conant (1928-1950) and the more recent excavations (Baud, 2000) in the abbey, have brought a large number of material, which has been studied. The 3D reconstitution was first concentrated on the architectural volume, then, in a second phase, it was possible to work on the internal decoration of the choir (marble pavement, apse decoration, furniture) and the aspect of both monumental carved façades (Romanesque portal, Gothic façade).

The documentation mentions the presence of approximately 300 monks at the beginning of the $12^{\text {th }}$ century, suggesting the presence of many seats in the sanctuary. We organized a system of stalls to contain at least 270 persons, supposing that some other monks were not always present, but occupied at other tasks. Since wooden furniture of this period has not been conserved, we invented a kind of simple chair, inspired from later examples in France.

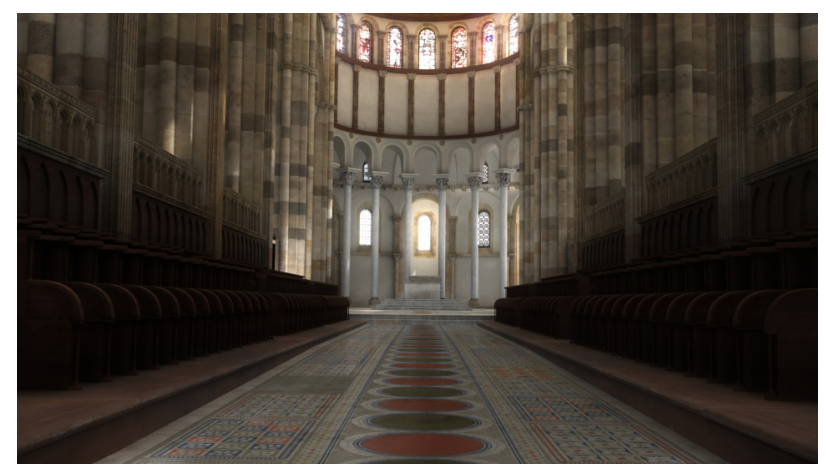


Figure 8. Rendering picture of the choir (pavement, stalls) (C) Arts et Métiers ParisTech, Centre des monuments nationaux, on situ

Another challenge was to reconstitute two monumental façades at the entrance of the church. The Romanesque façade (ca. 1115-1120) has been completely destroyed by explosive powder in the years $1790-1800$, but a description of the $18^{\text {th }}$ century and some iconographical documents give us a relatively precise description of this masterpiece. The interpretation of the engravings and watercolors is sometimes difficult, because of a certain inexactitude. We know that a Christ in Majesty was surrounded by the Evangelists (tympanum) and that the apostles occupied the lintel. About 400 pieces have survived from destruction, which represent about $5 \%$ of the entire portal. The archaeological study of this material and the research of polychromy have brought new information, which we included in the final mock up. For this part, an art historian and a laboratory ph-D student worked together in the museum for several months.

Many pieces are colored and allowed us to make a stratigraphical study to identify several periods. Four layers of color had to be analyzed, to distinguish the Romanesque layer, the Gothic repainting and the later layers (Rollier Hanselmann et al, 2010). Our goal was to reconstruct the original Romanesque polychromy, at least a part of it. The small article of H. Kleinschmidt indicated very bright colors, among which some have disappeared. The study of 200 additional fragments allowed us to give a relative precise state of the polychromy and to reconstruct it virtually. We know that the main figures were red, green and yellow on a blue background. The haloes were gilded on a red background. The laboratory analysis allows various verifications to certify the authenticity of these layers. Stratigraphical sequences of these samples were investigated on cross-section by optical microscopy and SEM-EDS analysis. Raman spectroscopy allowed us to identify the pigments. Physicochemical analysis point at the abundant use of relatively expensive materials, such as gold and tin leaves, lapis lazuli or cinnabar, which is even used as underlayer of gildings. This is not surprising, given that the abbey of Cluny was in the head of a vast European network, the Ecclesia Cluniacensis.

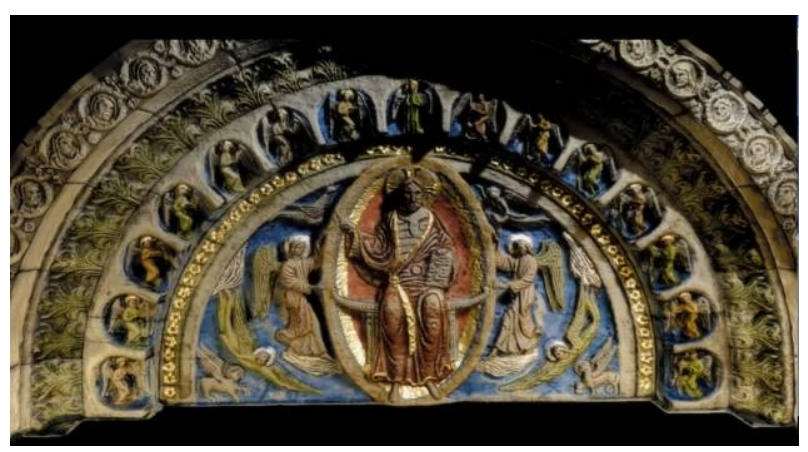

Figure 9. 3D polychromic tympanum

(c) Enodo, Arts et Métiers ParisTech, Centre des monuments nationaux, on situ

Around 2000 stone fragments, sometimes colored, had to be classified to recognize Romanesque from the Gothic pieces. The art historian had to distinguish between the Romanesque and the Gothic parts, and between the other parts of the antechurch (capitals, frieze, figures and vegetal elements). For the Gothic façade (mid $13^{\text {th }}$ century), some archeological blocks presented a curved shape which allowed us to reconstitute the precise dimension of a huge, 8 meters diameter, rose window
The final presentation of the $3 \mathrm{D}$ reconstitution of the church and its portal was then possible with different methods: mobile screens were put in the places where the usual touristic visit was difficult to understand. These 1,20 meter high devices show the formal state of the destroyed building and help for the understanding of the place.

An immersive room, with two screens, is another possibility, offering an itinerant exhibition to present various buildings and specific topics. The 3D vision of a masterpiece is created in real scale (1:1) so that the visitor can appreciate the hugeness of the medieval building.

A complete immersive room is also possible, to have a kind of fac-simile, of a place. We are now working on new methods to give the best rendering of ornamented grottoes, complicated painted chapels and all kind of medieval buildings.

We also managed another digital method for restitution: we achieved the digitization of the Romainmôtier Abbey (Switzerland) by the photogrammetric reconstitution. In this case, a series of photographs and some measuring of the buildings were sufficient to reconstitute the building.

\section{PERSPECTIVES AND FUTURE WORKS}

We currently aim at working on the modelled mock up in real time. For that target we settled an immersive room (LITE for Light Immersive Transportable Environment), allowing collaborative work around the digital mock-up. It is a tool for research and training. Indeed, we are currently leading experiments holding on several 3D engines (Virtools- VizardCry Engine) in order to compare them. Our target consists in enabling a virtual spatial realistic navigation in the church. Moreover, it is turned toward the temporal building's dimension, so that users can manage a 4D database. For achieving this objective, we take into account recent works (Stefani, 2010) holding on that topics.

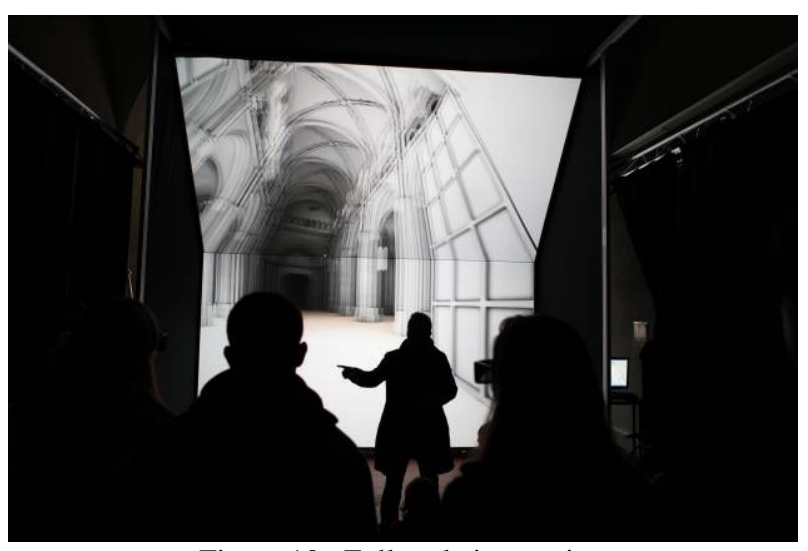

Figure 10. Full scale immersion

The interest of a multidisciplinary team is multiple. First it gives us the possibility to enrich the volumetric model, including archaeological scanned pieces. The comparisons between the ruins and the digital mock-up have led us to new observations, and allowed many adjustments between the different architectural parts. Medieval techniques can be revisited under diversified aspects.

Our research laboratory is involved in digital mock-up, virtual and Augmented Reality. Thus we focus on applying these concepts to our building. As a reminder, Augmented Reality aims at increasing the feeling that we have from our reality, by deceiving our senses. In our case this has been made possible by 
visual effects: Practically, three ray-on screens have been designed by on-situ and settled in pertinent locations in the ruins of the church, giving to tourists the ability to discover in situ missing parts of the building.

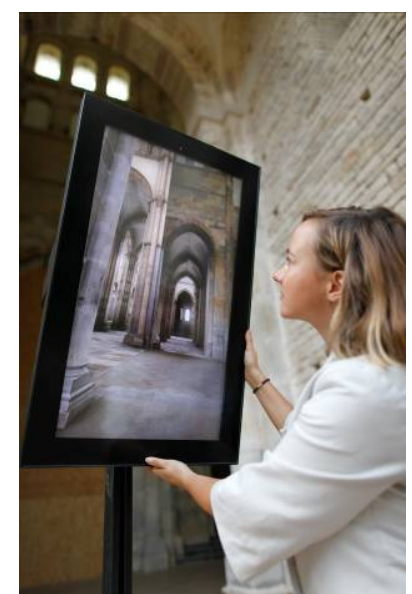

Figure 11. Augmented Reality device (designed by on-situ) (C) Arts et Métiers ParisTech, on situ, Centre des monuments nationaux

We first focused on viewing a partially destroyed building. Secondly, we pushed further the reflexion: What about enlarging the pipeline to complementary topics in architecture: viewing, inspecting, designing, maintaining, renewing. The perspectives supplied by Augmented Reality concept in this field are promising. As a consequence our team turned towards these topics: 2 engineers have been assigned to the development of new interacting methods with a 4D-model, in an Augmented Reality context. Researches are still in progress, holding on in situ interactions on digital mock-ups in a context of renovation works, and also on in situ visualization of thermal simulations. We are currently leading simultaneously two experiments:

The first one concerns the need for information, before a building's erection: How does an architectural project coexist with its close environment? It would also answer questions of the buildings' site specifications. This application, dedicated to architects and useful for town planners, is developed on mobile devices and acts as a decision-making tool.

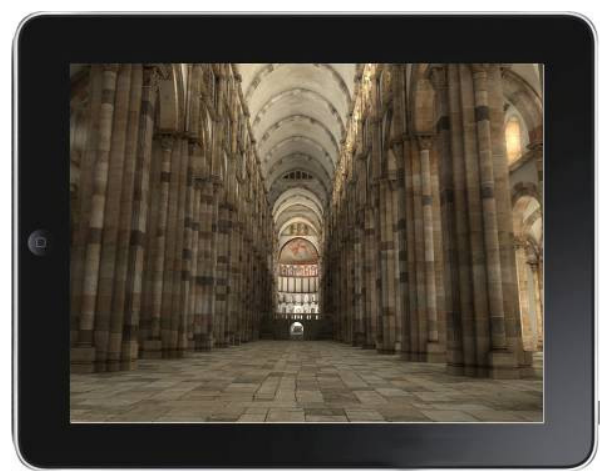

Figure 12. Mobile Augmented Reality device (perspective) (C) Arts et Métiers ParisTech, Centre des monuments nationaux, on situ

The second one occurs in maintaining context, especially on renovation works. Also developed on mobile devices, this application would consist in a construction-conducting tool. Dedicated to professional of the construction field, it would show 3D data on the mobile devices' screen to a geolocated operator. The data would be extracted from the whole digital database of the building and filtered according to the operator's skills and rights of access.

Cluny wants to be an outdoor laboratory of innovation, where its digital version and its data base will be used as a sandbox for various experimentations on site.

\section{REFERENCES}

\subsection{References and/or Selected Bibliography}

References from Journals:

Baud, A., 2000 : La Maior Ecclesia de Cluny : un exemple de construction horizontale, Comment construisait-on au Moyen Age ?, Dossier d'Archéologie, 251, pp. 34-35.

De Luca, L., Veron, P., Florenzano, M., 2006: Reverse engineering of architectural buildings based on a hybrid modeling approach, Computers \& Graphics, Elsevier, Vol 30, issue 2, pp. 160-176

De Luca, L., Véron, P., Florenzano, M., 2007 : A generic formalism for the semantic modeling and representation of architectural elements, The Visual Computer, Volume 23, number 3, pp. 181-205.

Happa, J., Mudge, M., Debattista, K., Artusi, A., Gonçalves, A., Chalmers, A., 2010 : Illuminating the past: state of the art, Virtual Reality, Vol 14, number 3, pp. 155-182.

Hvam, L., 1999 : A procedure for building product models. Robotics and Computer-Integrated Manufacturing, 15, pp. 7787

References from Books:

Conant, K.J., 1968 : Cluny, les églises et la maison du chef d'ordre.

Rollier-Hanselmann, J., Castandet, S., 2010 : Couleurs et dorures du portail roman de Cluny III. Restitution en 3D d'une œuvre disparue, Bulletin du Centre d'études médiévales Auxerre

Viollet-le-Duc, E., 1967 : Dictionnaire raisonné de l'architecture française du XIe au XVIe siècle, Editions. De Nobele, Paris.

\section{References from Other Literature:}

Chevrier, C., Maillard, Y., Perrin, J.P., 2009 : A method for the 3D modelling of historic monuments: the case of a gothic abbey church, IAPRS\&SIS, Vol 38(5), ISPRS Commission V - WG 4

Guarnieri, A., Pirotti, F., Vettore, A., 2009 : An Open source application for interactive exploration of Cultural Heritage 3D models on the web IAPRS\&SIS, Vol 38(5), ISPRS Commission V - WG 4

Père, C, Landrieu J., Rollier-Hanselmann, J., 2009 : «Reconstitution virtuelle de l'église abbatiale de Cluny III : Des fouilles archéologiques aux algorithmes de l'imagerie », Actes du colloque Virtual Retrospect, p. 151-160.

Remondino, F., El-Hakim, S., Girardi, S., Rizzi, A., Benedetti, S., Gonzo, L., 2009 : 3D Virtual reconstruction and visualization of complex architectures - The 3D-ARCH project, IAPRS\&SIS, Vol 38(5), ISPRS Commission V - WG 4 
Stamos, I, 2009 : Automated 3D modelling of urban environments, IAPRS\&SIS, Vol 38(5), ISPRS Commission V WG 4

Stefani, C., 2010 : Maquette numérique spatio-temporelles d'édifices patrimoniaux. Modélisation de la dimension temporelle et multi-restitutions des édifices, mémoire de thèse de doctorat, école doctorale ${ }^{\circ} 432$ : SMI

\section{References from websites:}

GML, 2008 : The Generative Modeling Language enables to create fully parametric $3 \mathrm{D}$ objects.

http://www.generative-modeling.org/GenerativeModeling/Gml.html

(Accessed February 2011)

Mérimée : The name of a classification established by the French Culture ministry in the $19^{\text {th }}$ century: It sorts buildings according to their nature and type of architecture (civil, religious...)

http://www.culture.gouv.fr/culture/inventai/patrimoine/

(Accessed February 2011)

Metris Model-Maker MMD50 and MMD100 specifications: http://en.souvr.com/product/200905/1919.html

(Accessed February 2011)

Trimble : http://www.trimble.com/gs200.shtml

(Accessed February 2011)

\section{ACKNOWLEDGEMENTS}

The project could not take place without the support and help of the "Ministère de la Culture ", the "Conseil Régional de Bourgogne », the "Conseil Général de Saône et Loire », the " Mairie de Cluny », the «Centre des Monuments Nationaux », the «Direction Régionale des Affaires Culturelles (DRAC) et de la Communication de Bourgogne », the «Secrétariat Général des Affaires Régionales de Bourgogne », the "Union Européenne », the « Musée d'Art et d'Archéologie de Cluny », the « Centre d'Etudes Clunisiennes », « On-Situ », « Dynamic 3D », the «Fédération des Sites Clunisiens », the « Office du Tourisme de Cluny ». Last but not least, we would like to thank personally Zoe Petty, for her discreet but powerful contribution to this article. 